\title{
The films of Wim Wenders
}

Sean Spence asks what the films of lopsed medic Wim Wenders are telling brain imagers.

For the devotee of Wim Wenders, the German film director, London was the place to be this summer. The National Film Theatre showed all his films, his latest ('Far Away, So Close') opened, and the full five hour cut of 'Until the End of the World', was shown in July.

Wenders, the ex-medical, ex-theology student, whose films explore the hinterland of consciousness, the modern world of images, and the inner world of speech, lent his own print of this film for a special showing. For contractual reasons it may never be shown again.

Where 'Wings of Desire' and 'Far Away. So Close' lend mankind the aid of messengers, angels who overhear our thoughts, 'Until the End of the World' sees man in a world of his own creation, obsessed with himself. We are in the year 1999, and a nuclear satellite is spinning out of control through the atmosphere. Video-fax, telecommunication, sinister video and computer surveillance insinuate themselves into a claustrophobic world.

Claire (played by Wenders' nurse Solveig Donmartin) follows a stranger across the world, from Venice through Paris, Berlin, Tokyo, on eventually to Australia. All the while he is obsessively filming his relatives' faces. His intention is to record these images so that his blind mother might see. His ophthalmologist father Henry Farber is in hiding in the Australian outback, perfecting a machine that will allow vision by direct neuronal interaction.

But something goes wrong. The task of lending sight becomes perverted and we enter a quest for the imaging of dreams. Farber invokes Jung and Freud as he stares maniacally at a screen, claiming to have imaged the human soul. Although Claire resists she eventually succumbs, records her dreams and becomes obsessed with their repetition. The main protagonists develop a malignant narcissism which renders them impervious to others.

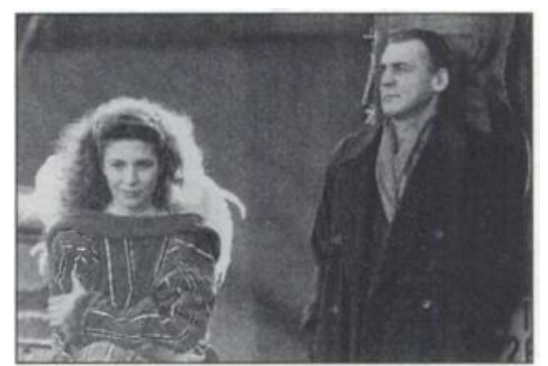

Solveig Donmartin and Bruno Ganz in 'Wings of Desire' ('Himmel uber Berlin'). National Film Archive London.

Throughout, Claire's former partner observes all, recording events in a novel he is writing. He is the counterpart of the angels in 'Wings of Desire' who record all events occurring in mortal time. Humour and music surface in this extended version, but the prevailing theme is man's folly in his search for personal glory.

In 'Far Away, So Close' the angels recite "we are not the message, we are the messengers". Wenders' message is that man neglects the medium of life, sacrificing that which he already has (the senses, relationships, cognizance of life on Earth) and instead pursues his preoccupations to their ultimate sterility. Beware of the barrenness of the busy life.

His questioning of our belief in images is timely. For scientists engaged in the imaging of human cognition the resonances are clear. We can see ourselves thinking, we can 'explain' what we see, but we are still working at the level of associations. The value of such work will depend on what our images enable us to do; to diagnose, to treat, or to arrive at colour phrenology.

Sean A. Spence, Research Fellow, MRC Clinical Sciences Centre, Royal Postgraduate Medical School, Hammersmith Hospital, London W12 ONN 